\title{
EEN EN ANDER UIT DE GESCHIEDENIS DER STAATSPENSIOENFONDSEN VOOR DE BURGERLIJKE AMBTENAREN.
}

\section{1.}

De Commissie van 1878 had voor haar arbeid, het onderzoek naar de grondslagen, waarop aan weduwen en weezen van alle burgerlijke ambtenaren van het Rijk, pensioen verleend zoude kunnen worden, en naar de grondslagen van het toenmaals bestaande weduwenfonds, in de eerste plaats goede sterftetafels noodig.

$\mathrm{Nu}$ moet een goede sterftetafel berusten op de waarneming van een groot aantal personen, welke:

$1 \mathrm{e}$ in de zelfde landstreek wonen als zij, voor wie men de berekening wil toepassen;

$2^{\text {e }}$ die ongeveer in dezelfde levensomstandigheden verkeeren, en dus ook

$3^{\mathrm{e}}$ niet te lang geleden geleefd hebben.

Buitenlandsche sterftetafels zijn dus in het algemeen niet bruikbaar; een sterftetafel uit de geheele bevolking van Nederland opgemaakt, is a priori niet van toepassing op een speciaal deel dier bevolking, in casu de ambtenaren; de sterftetafel van mannen is anders dan die van vrouwen; tafels, opgemaakt uit gegevens van vele jaren her of uit een tijdperk van langen duur, zijn niet wel bruikbaar; de laatste niet, omdat de sterfte in dat lange tijdperk mogelijk niet hetzelfde is gebleven en het midden van zulk een tijdperk lang achter ons ligt.

Aangezien geen statistiek van ambtenaren bestond, moest een sterftetafel gezocht worden, welke zoo goed mogelijk aan de hiervoren opgegeven eischen voldeed.

Hiertoe werden genomen de sterftetafels voor het geheele Rijk, volgens de geslachten gescheiden, afgeleid uit de volkstellingen van 1860 en 1869 , en de, tusschen deze tijdstippen waargenomen, sterfte, waarbij de gegevens, op aanwijzing der commissie opnieuw werden bewerkt. 
Ofschoon er werd verwacht, dat de gebruikte sterftetafels niet veel verschillen zouden met de werkelijke sterfte onder de ambtenaren, zoo werd toch door de commissie van veel belang geacht, dat de sterfte van het ambtenaarspersoneel geregeld zou worden opgenomen. Ook werd toen (1878) reeds door de commissie aangeraden den stand van het op te richten weduwen pensioenfonds, b.v. elke vijf jaar volgens wiskunstige regels te onderzoeken en bij dat onderzoek dan zoo mogelijk betere sterftetafels te gebruiken. Zulks is dan ook geschied. Het is alleen te betreuren dat vele pensioenfondsen, zoowel Rijks- als particuliere, dit voorbeeld niet of eerst laat gevolgd hebben.

Bij de behandeling der pensioenwetten van 1890 in de Tweede Kamer, werd er door de Regeering al op gevezen, dat de uitkomsten, na 1878 verkregen, een veel kleiner sterfte aanwezen, dan bij de vroegere berekeningen verondersteld was.

Voor het opmaken der eerste wetenschappelijke baians van het Pensioenfonds, geldende voor 31 December 1895, kon reeds gebruik gemaakt worden van gegevens omtrent de mannelijke ambtenaren verzameld, en wel van 1878 tot 1895. Betreffende de vrouwelijke ambtenaren stonden geen voldoende gegevens ten dienste en werd er gebruik gemaakt van de sterftetafels betreffende de vrouwen der 20 voornaamste gemeenten (1870-1879) en, voor vrouwen boven de 50 jaar, van de sterftetafels, afgeleid uit de lijfrentetreksters der Hollandsche Societeit van Levensverzekeringen.

De tweede en de derde wetenschappelijke balans werden met dezelfde gegeveris, aangevuld met de nieuwe waarnemingen, resp. tot 1901 en 1906, berekend. Bij de samenstelling der vierde wetenschappelijke balans werd voor de mannen slechts gebruik gemaakt van gegevens, die betrekking hadden op het tijdvak van 1 Januari 1891 tot 1 Januari 1911. De daaruit afgeleide sterftetafel zal het verloop in de naaste toekomst beter weergeven, nu de vroegere jaren (1878-1891) met hun verouderde waarnemingen niet zijn gebruikt. Voor de sterftetafel der vrouwen moest, evenals bij de vorige balansen, nog gebruik gemaakt worden van gegevens buiten deelgerechtigden van het fonds omdat het getal der beschikbaren te gering was. 
Hieronder moge een vergelijk volgen van de sterftetafels, die op verschillende tijdstippen samengesteld zijn.

- A. M a nne n.

\begin{tabular}{|c|c|c|c|c|c|c|c|c|}
\hline \multirow{2}{*}{ 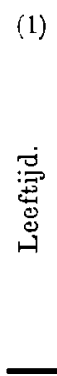 } & \multicolumn{2}{|c|}{$\begin{array}{c}(2) \\
\text { Staats- } \\
\text { commissic } \\
1878 . \\
(1660-1869) .\end{array}$} & \multicolumn{2}{|c|}{$\begin{array}{c}(\dot{3}) \\
\text { Eerste } \\
\text { Ambtenaren- } \\
\text { Tafel. } \\
\text { (1878-1894). }\end{array}$} & \multicolumn{2}{|c|}{$\begin{array}{c}(4) \\
\text { Vierde } \\
\text { Ambtenaren- } \\
\text { Tafel. } \\
\text { (L891-1909). }\end{array}$} & \multicolumn{2}{|c|}{\begin{tabular}{|c}
$(5)$ \\
Geheele \\
bevolking van \\
Nederland. \\
$(1900-1909)$.
\end{tabular}} \\
\hline & $\begin{array}{c}\text { Jaarl. } \\
\text { sterfte } \\
\text { op } \\
10.000 \\
\text { per- } \\
\text { sonen. }\end{array}$ & $\begin{array}{l}\text { Ge. } \\
\text { midd. } \\
\text { levens- } \\
\text { duur. }\end{array}$ & $\begin{array}{c}\text { Jaarl. } \\
\text { sterfte } \\
\text { op } \\
10.000 \\
\text { per- } \\
\text { sonen. }\end{array}$ & $\begin{array}{l}\text { Ge. } \\
\text { midd. } \\
\text { le rens. } \\
\text { duur. }\end{array}$ & $\begin{array}{l}\text { Jaarl. } \\
\text { sterfte } \\
\text { op } \\
10.000 \\
\text { per- } \\
\text { sonen. }\end{array}$ & $\begin{array}{c}\text { Ge- } \\
\text { midd. } \\
\text { levens } \\
\text { duur. }\end{array}$ & \begin{tabular}{|c} 
Jaarl. \\
sterfte \\
op \\
10.000 \\
per- \\
sonen.
\end{tabular} & $\begin{array}{l}\text { Ge- } \\
\text { midd. } \\
\text { levens } \\
\text { duur. }\end{array}$ \\
\hline & 0 & 8 & - & - & 47 & 43.1 & 50 & 45 \\
\hline 0 & 93 & 32.8 & 54 & 37.1 & 34 & 38.9 & 48 & 37. \\
\hline 0 & 124 & 25.8 & 73 & 29.1 & 53 & 30.3 & 68 & $29 . \overline{0}$ \\
\hline U & 191 & 19.2 & 133 & 91.5 & 110 & 22.2 & 118 & 21.8 \\
\hline 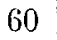 & 340 & 13.2 & 250 & 14.7 & $23 \check{5}$ & 15.1 & 243 & 14.7 \\
\hline 0 & 695 & 8.2 & 576 & 8.9 & 560 & 9.2 & 575 & 8.9 \\
\hline 0 & 1495 & 4.6 & 1360 & 4.9 & 1240 & 5.4 & 1370 & 4.9 \\
\hline
\end{tabular}

B. Vrouwen.

\begin{tabular}{|c|c|c|c|c|c|c|c|c|}
\hline \multirow{2}{*}{ 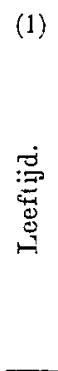 } & \multicolumn{2}{|c|}{$\begin{array}{c}(2) \\
\text { Stats- } \\
\text { commissie } \\
1878 \\
(1860-1869) .\end{array}$} & \multicolumn{2}{|c|}{$\begin{array}{c}(3) \\
\text { Eerste } \\
\text { Weduwen- } \\
\text { Tafel. } \\
\text { (1891-1.899). }\end{array}$} & \multicolumn{2}{|c|}{$\begin{array}{c}( \pm) \\
\text { Derde } \\
\text { Weduwen- } \\
\text { Tafel. } \\
(189 t-1909) .\end{array}$} & \multicolumn{2}{|c|}{$\begin{array}{c}(5) \\
\text { Geheele } \\
\text { berolking van } \\
\text { Nederland. } \\
(1900-1909) .\end{array}$} \\
\hline & $\begin{array}{c}\text { Jaarl. } \\
\text { sterfte } \\
\text { op } \\
10.000 \\
\text { per- } \\
\text { sonen. }\end{array}$ & $\begin{array}{l}\text { Ge- } \\
\text { midd. } \\
\text { levens- } \\
\text { duur. }\end{array}$ & $\begin{array}{c}\text { Jaarl. } \\
\text { sterfte } \\
\text { op } \\
10.000 \\
\text { per- } \\
\text { sonen. }\end{array}$ & $\begin{array}{c}\text { Ge- } \\
\text { midd. } \\
\text { levens- } \\
\text { duur. }\end{array}$ & $\begin{array}{c}\text { Jaarl. } \\
\text { sterfte } \\
\text { op } \\
10.000 \\
\text { jel- } \\
\text { sonen. }\end{array}$ & $\begin{array}{l}\text { Ge- } \\
\text { midd. } \\
\text { levens- } \\
\text { duur. }\end{array}$ & $\begin{array}{c}\text { Jaarl. } \\
\text { sterfte } \\
\text { op } \\
10.000 \\
\text { per- } \\
\text { sonen. }\end{array}$ & $\begin{array}{c}\text { Ge- } \\
\text { midd. } \\
\text { levens- } \\
\text { duur. }\end{array}$ \\
\hline 20 & 71 & 40.1 & 59 & 44.7 & 38 & 47.4 & 38 & 46.9 \\
\hline 30 & 108 & 33.3 & 73 & 37.4 & 46 & 39.2 & 52 & 38.8 \\
\hline 40 & 142 & 27.1 & 90 & 30.1 & 70 & 31.1 & 71 & 30.8 \\
\hline 50 & $15 \pm$ & 20.4 & 120 & 22.7 & 108 & 23.5 & 101 & 22.9 \\
\hline 60 & 281 & 13.8 & 230 & 15.8 & 198 & 16.1 & 208 & 15.5 \\
\hline 70 & $65 \overline{5}$ & 8.4 & 499 & 9.9 & 485 & 10.0 & $\overline{5} 17$ & 9.4 \\
\hline 80 & 1465 & 4.8 & 1139 & 5.6 & 1112 & 5.7 & 1280 & 5.2 \\
\hline 90 & 2680 & 2.8 & 2556 & 2.8 & 2420 & 3.0 & 2700 & 2.4 \\
\hline
\end{tabular}

Uit bovenstaande tafels blijkt, dat de vrouwen een kleiner sterftekans en dus een langeren gemiddelden levensduur hebben, dan de mannen van denzelfden leeftijd. 
Vergelijkt men de cijfers van kolom 2 met die van kolom 3, dan valt op dat de sterfte door de Commissie van 1878 te hoog geraamd was, ook al neemt men in aanmerking, dat de sterfte in den loop der tijden afneemt, zooals blijkt uit vergelijking van de kolommen 2 en 5 . Deze beide hebben betrekking op een zelfde soort personen, de geheele bevolking van Nederland, gescheiden naar de geslachten. De afname van de sterfte blijkt op dezelfde gronden ook uit een vergelijking der kolommen 3 en 4.

Nog sterker komt de vermindering der sterfte uit, als men die over een groot aantal jaren volgt van de bevolking van Nederland.

Op 1000 inwoners bedroeg die sterfte:

\begin{tabular}{|c|c|c|c|}
\hline tijdvak & mannen & vrouwen & manuen en vrouwen \\
\hline $1840-' 49$ & 27.65 & 25.59 & 26.56 \\
\hline $1850-' 59$ & 26.16 & 24.80 & 25.49 \\
\hline $1860-' 69$ & 25.40 & 24.92 & 24.80 \\
\hline $1870-79$ & 25.28 & 23.57 & 24.49 \\
\hline 1880 -' 89 & 22.19 & 20.39 & 21.27 \\
\hline $1890-99$ & 19.36 & $\cdot 17.87$ & 18.67 \\
\hline $1900-04$ & 17.26 & 15.88 & 16.57 \\
\hline $1905-09$ & 15.12 & 14.25 & 14.69 \\
\hline het jaar 1910 & 13.93 & 13.10 & 13.55 \\
\hline$\gg \gg 1911$ & 14.95 & 14.09 & $14.501)$ \\
\hline
\end{tabular}

De invloed van de verminderde sterfte op een weduwenen weezenpensioenfonds zal zijn, dat de vrouwen gemiddeld op later leeftijd weduwe, de kinderen op later leeftijd wees worden, terwijl de bijdragen van de mannen, die gemiddeld een hoogeren leeftijd bereiken, langer in het fonds vloeien.

$\mathrm{Nu}$ is wel de gemiddelde leeftijd der vrouwen grooter geworden, maar doordat zij gemiddeld op later leeftijd weduwe zijn geworden, is het aantal jaren, waarin zij pensioen trekken, niet noemenswaard vermeerderd. Door het toepassen van nieuw opgemaakte sterftekansen kon de contante waarde der lasten van de tegenwoordige en van de vroegere ambtenaren, na aftrek van de contante waarde der toekomstige baten op de vierde wetenschappelijke balans \pm f 3.211.100 lager geraamd worden.

Behalve den invloed van een vermindering in de sterfte heeft het Pensioenfonds dien van de verandering van den

1) De groote sterfte in 1911 is v.n.l. veroorzaakt door de belangrijke kindersterfte, een gevolg van den buitengewoon warmen zomer. 
rentevoet in den loop der jaren ondervonden. De Commissie van 1878 nam een rentevoet van $4 \mathrm{pCt}$. aan. In de toenmalige tijdsomstandigheden zag zij geen reden om van den (toendertijd) in ons land bijna officieelen rentevoet af te gaan en een lagere rente vast te stellen voor hare berekeningen. „Bij het opmaken der achtereenvolgende wetenschappelijke balansen zal men", sprak de Commissie zich uit, „vanzelf op den rentevoet te letten hebben, en waar geheel veranderde toestanden ontstaan, moeten ook de grondslagen veranderen." De toekomst bewees, dat deze inzichten juist waren. Wel kon de commissie van 1881 nog een rentevoet van $4 \mathrm{pCt}$. handhaven, ofschoon de koers der Nederlandsche Staatspapieren zóó was, dat geen $4 \mathrm{pCt}$. van een kapitaal, uitsluitend in deze waarde belegd, gemaakt kon worden, maar bij het indienen der pensioenwetten in 1890 moesten de berekeningen opnieuw geschieden, daar de rentevoet toen al tot $3 \frac{1}{2}$ pCt. gedaald was. $\mathrm{Bij}$ het opmaken der eerste wetenschappelijke balans van het Pensioenfonds in 1896 moest $3 \mathrm{pCt}$. rente gerekend worden. In het jaar te voren had dan ook de conversie der Nederlandsche $3 \frac{1}{2}$ pCt. leeningen in 3 pCt. plaats gehad. (Deze had het pensioenfonds een jaarlijksch renteverlies van $f 35.000$ berokkend.) Verlaging van den rentevoet tot $2 ! \mathrm{pCt}$. werd toen zelfs zeer waarschijnlijk geacht.

En ziet, tien jaren later werd de derde wetenschappelijke balans volgens een rentevoet van $3 \frac{1}{2} \mathrm{pCt}$. berekend, daar die toen veilig daarop gesteld kon worden.

Om vergelijking met de vorige balansen mogelijk te maken, werd de balans ook opgemaakt voor $3 \mathrm{pCt}$. rentevoet. Duidelijk kwam daarbij de invloed van den gewijzigden rentestandaard uit. Toonde de balans, opgemaakt volgens $3 \mathrm{pCt}$. rente een $\mathrm{n}$ adeelig saldo van f 921.478.dezelfde berekeningen, uitgevoerd met $3 \frac{1}{2} \mathrm{pCt}$. rente, gaven een voordeelig saldo van f 4.652.872.-

De vierde wetenschappelijke balans werd eveneens opgemaakt met $3 ! \mathrm{pCt}$. rente, ofschoon toen, 31 December 1910, de geldmarkt een soliede belegging op een rentevoet, die de $4 \mathrm{pCt}$. naderde veroorloofde. Zulks hield verband met de beleggingen van het Pensioenfonds.

Vroeger, en dat is nog niet zoo heel lang geleden, 
heerschte algemeen het begrip, dat een fonds, als het "Pensioenfonds", zijn gelden uitsluitend moest beleggen in Nationale Schuld. ${ }^{1}$ ) Gedeeltelijk was hierbij van de Regeering de bedoeling het Staatscrediet op te houden.

De "Weduwenwet voor de ambtenaren van 1890 " schreef de uitsluitende belegging in Nat. Werkel. Schuld nog imperatief voor, en eerst bij de wet van 29 Juni 1899 werd het beleggingsveld uitgebreid. Een bedrag van nominaal 48 millioen gulden, de toenmalige bezitting van het fonds, moet volgens die wet belegd worden in Nationale Schuld, voor het meerdere kon de belegging geschieden in binnenen buitenlandsche effecten en in eerste hypotheken op onroerende goederen in Nederland. Telken jare wordt een lijst der fondsen, die voor belegging in aanmerking komen, aan de goedkeuring van den Minister van Financien onderworpen. Op deze wijze is een soliede belegging gewaarborgd en tevens de mogelijkheid geopend om een hooger rente te bedingen dan bij den uitsluitenden aankoop van Nationale Werkelijke Schuld.

Een goed finantiëel beheer eischt bovendien belegging in verschillende soort van waarden en een verdeeling van het bezit, zoowel over effecten als over hypotheken. De laatste jaren werd dan ook deelgenomen aan leeningen van Nederlandsche provincien en gemeenten, waardoor iets meer dan $4 \mathrm{pCt}$. rente van deze beleggingen kon gemaakt worden en in 1910 werden voor het eerst hypotheken gesloten, welke $4 \frac{1}{4} \mathrm{pCt}$. opbrachten.

Het opmaken van de balans van een handelslichaam heeft ten doel te komen tot de winst of het verlies; de posten, welke er op voorkomen, behooren geboekt te zijn volgens de waarde, die zij hebben op den balansdag; de effecten dus op de beurswaarde van dien dag. Bij een groot effectenbezit kan de beurswaarde op een zelfden datum van achtereenvolgende jaren belangrijk uiteenloopen, terwijl waar niet gerealiseerd wordt, de winst of het verlies, ontstaan door koersverschil, eigenlijk fictief is. Daarom hebben lichamen als levensverzekeringmaatschappijen, die

1) In de regeling van het pensioenfonds der gemeente Amsterdam is nog voorgeschreven: De roor belegging beschikbare baten van het fonds worden gebruikt tot inkoop van Gemeenteschuld. 
een groote effectenportefeuille hebben, veelal een reservepost op de balans, die ten doel heeft de gevolgen van het koersverschil op de waarde der effecten op te nemen. Heeft het effectenbezit tengevolge der lage koersen een waardeverlies ondergaan, dan behoeft, met zulk een post op de balans, de gemaakte winst niet te verminderen, maar wordt dit op dien post verhaald, hetgeen veilig kan geschieden, als er maar kans is, dat de lage koersen zich zullen herstellen, of die post groot genoeg is.

Bij het Pensioenfonds heeft de balans niet het doel de winst of het verlies aan te duiden, doch slechts om na te gaan of de grondslagen, waarop het fonds berust, nog doeltreffend zijn, dat dus de toekomstige lasten gedekt worden door de toekomstige baten en de waarde van het bezit. Waar deze lasten en baten gedisconteerd zijn voor een rentevoet van $3 \frac{1}{2} \mathrm{pCt}$. ligt het in de rede die rente ook voor het effectenbezit aan te nemen.

De certificaten $2 \frac{1}{2}$ pCt. Nat. W. S. zijn dan ook op de balans geboekt tegen een koers van $71 \frac{3}{7}$, de $3 \mathrm{pCt}$. tegen een koers van $85 \frac{5}{7},{ }^{1}$ ) de $3 \frac{1}{2}$ en 4 pCt. provinciale en gemeentelijke leeningen a pari geboekt, de overige effecten tegen de beurswaarde op ulto. December, tenzij deze toen hooger was dan de nominale waarde, in welk geval de laatste is aangenomen. De balanswaarde der effecten is door deze wijze van rekenen f 597.778. - lager dan de beurswaarde op den balansdag.

Van het kapitaal, volgens balanswaarde groot $f$ 53.087.574.-, volgens beurswaarde groot $f$ 53.685.352.-, wordt een rente van f 1.891.478. - gekweekt, overeenkomende met 3.56 pCt. van de balanswaarde of 3.50 pCt. van de beurswaarde.

Mocht de tegenwoordige hoogere rentevoet van $4 \mathrm{pCt}$. van blijvenden aard blijken, dan zal van de nieuwe beleggingen meer rente gemaakt worden, maar de beurswaarde van het oude effectenbezit dalen. Het evenwicht van de balans zal niet verbroken worden, zoolang de toekomstige baten en lasten ook tegen $3 \frac{1}{2} \mathrm{pCt}$. gedisconteerd worden.

1) In begin Juni 1912 was de koers van de certificaten $2 \frac{1}{2} \mathrm{pCt}$. Nat. W. S., $67 \frac{1}{2}$ pCt., der 3 pCt.: 805 pCt.; op 31 December 1910 resp. $72 \frac{5}{8}$ en $88 \frac{1}{9}$ pCt. 
Gaat men over tot een rentevoet van $4 \mathrm{pCt}$., wat voorshands nog niet geraden is, dan moet de balanswaarde van het kapitaal tegen een rente van $4 \mathrm{pCt}$. berekend worden en dus aanmerkelijk dalen, doch daartegenover staat, dat evenals bij de derde wetenschappelijke balans, toen van $3 \mathrm{pCt}$. overgegaan werd tot $3 \frac{1}{2} \mathrm{pCt}$. rente, door het tegen een hooger interest disconteeren der toekomstige baten (wier contante waarde daardoor hooger wordt) en der toekomstige lasten (wier contante waarde daardoor lager wordt) het verschil tusschen deze; hetgeen gedekt moet worden door het bezit van het Pensioenfonds, ook aanmerkelijk geringer zal zijn:

Bij de oprichting van het Pensioenfonds had het kapitaal, overgenomen van het Pensioenfonds voor Burgerlijke Ambtenaren, een nominale waarde van $f 40.447 .700$ en bestond uit:

f $31.246 .1002 \frac{1}{2}$ pCt. Inschrijvingen Nat. W. S.

" 5.581.300 $3 \mathrm{pCt}$.

" 3.620.300 3! pCt.

Op ulto December 1910 was het bezit belegd voor:

38.9 millioen gulden in inschrijvingen Nat. W. S.

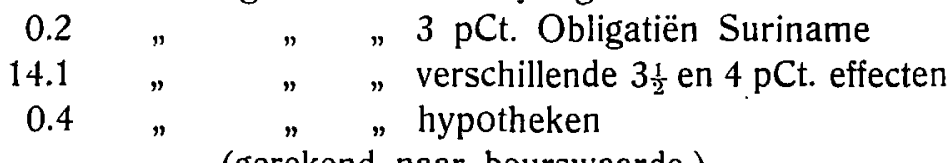

(gerekend naar beurswaarde.)

Het nominaal bedrag der inschrijvingen Nat. W. S. bedroeg 50 millioen gulden, dus iets meer dan de verplichte 48 millioen.

De eerste wetenschappelijke balans sloot met een voordeelig saldo van 14.7 millioen gulden. Over een gedeelte van dat bedrag werd beschikt om de weduwen der, vóór de indiening der weduwenwet (10 December 1881) overleden, ambtenaren hetzelfde pensioen te geven als die der na dat tijdstip overleden ambtenaren. Door deze weduwen toch werd, bij de oprichting van het Pensioenfonds, slechts recht verkregen op $\frac{2}{3}$ ivan het pensioen van de weduwen der bestaande ambtenaren, en zulks voorzichtigheidshalve.

Overigens werd een voordeelig saldo noodig geacht, zoowel omdat de Regeering zich de beschikking voorbehouden had van 4 millioen gulden, afkomstig van het 
voormalige Pensioenfonds der Burgerlijke Ambtenaren, als omdat verdere verlaging van den rentestandaard niet onmogelijk werd geacht.

Op de tweede wetenschappelijke balans was het voordeelig saldo toegenomen tot ruim 18 millioen gulden, waardoor het mogelijk werd geacht de pensioenen te verhoogen. Zulks geschiedde bij de wet van 5 Juni 1905, Staatsblad No. 156 , en wel met 15 pCt., ingaande op den 1en Januari 1905. Het maximum van het weduwenpensioen werd daardoor van f 600 . - op f 690.- gebracht. Evenzoo het kindergeld.

Evenwel wees de derde wetenschappelijke balans een nadeelig saldo van ruim 9 ton aan, zoodat, had men niet kunnen overgaan tot een hoogeren rentevoet, waardoor dit nadeelig saldo omgezet werd in een voordeelig saldo van ruim 4.6 millioen gulden, de pensioenen verminderd of de bijdragen verhoogd hadden moeten worden. Nu bestond hiervoor geen gevaar. Bovendien beschikte het Rijk nog niet over de het toekomende 4 millioen. Dit kapitaal bleef voorloopig in het bezit van het Pensioenfonds ofschoon jaarlijks aan rente daarvoor $f$ 125.000. - aan het Rijk werd uitgekeerd.

Ten slotte, de vierde balans wijst een voordeelig saldo van ruim $10 \frac{3}{4}$ millioen gulden aan. De post van 4 millioen gulden komt op deze balans niet meer voor. De wet van 5 Juni 1905 (Staatsblad No. 153) waarbij de onderwijzers, verbonden aan het openbaar en aan het bizonder onderwijs, deelgerechtigd werden aan het Pensionenfonds, hief tevens de bepaling op dat het Rijk over bedoelde 4 millioen kon beschikken.

Het lag in het voornemen van het Bestuur om, naar aanleiding van het batig saldo, een voorstel te doen aan den Minister van Financien om de pensioenen te verhoogen.

Inderdaad zou zulks een weldaad zijn, warit de pensioenen der weduwen zijn laag. Wel heeft de oprichting van het pensioenfonds het denkbeeld, om de nagelaten betrekkingen der ambtenaren voor gebrek te vrijwaren, tot grondslag gehad, maar, met een maximum van $f$ 690.is toch maar het gemiddelde der weduwenpensioenen, f 323.- Een verhooging zal dus zeer welkom zijn niet 
alleen, maar alleszins verantwoord, waar de levensstandaard in de laatste 10 jaren zooveel hooger is geworden.

De vrouwelijke ambtenaren, sedert 1 Januari 1906 ook de onderwijzeressen, storten voor het pensioen harer eventueele weezen $1^{\circ} \mathrm{pCt}$. van haar traktement. Aangezien velen den dienst op jeugdigen leeftijd verlaten en slechts zeer weinigen pensioentrekkende weezen nalaten, overtreffen de toekomstige baten de toekomstige lasten met een groot bedrag, n.l. ruim 4.7 ton gouds.

Hare contributie zou dus aanzienlijk verlaagd kunnen worden. Komt evenwel het aanhangig wetsontwerp, waarbij de vrouwelijke ambtenaar of onderwijzeres bij huwelijk wordt ontslagen, tot stand, dan zal dientengevolge de geheele bijdrage van de vrouwelijke ambtenaren en onderwijzeressen dienen te vervallen. Wordt het ontslag bij huwelijk voor de onderwijzeressen bij het bizonder onderwijs niet verplichtend gesteld, en dit ligt niet in de bedoeling van het wetsontwerp, dan za! voor dezen de deelneming in het pensioenfonds moeten open blijven.

Nog een enkel woord over het verloop van het aantal deelgerechtigden en den invloed er van op het Pensioenfonds.

Op den 1 en Januari 1878 waren in dienst 12416 ambtenaren, waaronder 50 vrouwen; op ulto. December 1895 , bij het opmaken van de eerste wetenschappelijke balans was dit aantal vermeerderd tot 17626, waaronder 267 vrouwen, terwijl het korps burgerlijke ambtenaren op 31 December 1910 bestond uit 29170 mannen en 1639 vrouwen.

Behalve deze groote toeneming van ambtenaren, valt op, het aanmerkelijk grooter aantal vrouwelijke ambtenaren; wier toeneming veel grooter is dan die der mannen. Toch is het aantal vrouwelijke ambtenaren tot de mannelijke bij de Gemeenten grooter n.l. 14.0 pCt. ${ }^{1}$ ) tegen 5.6 pCt. van het aantal mannelijke ambtenaren in 's Rijks dienst.

Van den beginne af, werd er op een toeneming van het aantal ambtenaren gerekend, welke afgeleid werd uit een statistiek over de laatst verloopen jaren. Zoo bedroeg het

1) Dit getal geldt voor 31 December 1907, toen de gezamenlijke gemeenten 37946 mannelijke en 5318 vrouwelijke ambtenaren in dienst hadden. 
aantal nieuw benoemde mannelijke ambtenaren over het tijdvak 1892-'95 gemiddeld 859 per jaar, terwijl gemiddeld 145 per jaar den dienst verlieten, zonder recht op weduwenpensioen. Over 1906-'10 werden gemiddeld 1453 mannelijke ambtenaren aangesteld en traden 54 uit het Pensioenfonds voor weduwen en weezen.

Maar behalve dat het aantal deelgerechtigden in het fonds toenam door nieuwe aanstellingen, werden soms geheele categoriën personen door de Regeering deelgerechtigd gemaakt. Zoo werden, met ingang van 1 Januari 1906, alle leeraren der gemeente Hoogere Burger Scholen opgenomen in het Pensioenfonds; in datzelfde jaar had de opneming plaats van het personeel van het middelbaar en voorbereidend hooger onderwijs, benevens het personeel, werkzaam bij de Landsdrukkerij. Zoo werd, bij Koninklijk Besluit in 1909 , bepaald dat de onderwijzers bij de Rijksnormaallessen, van Juli 1881 af, als burgerlijke ambtenaren hadden moeten worden beschouwd. Deze veranderde beschouwing heeft het Pensioenfonds ongeveer 1 millioen gulden gekost. Begrijpelijkerwijze moesten nieuwe takken van dienst het aantal deelgerechtigden sterk doen stijgen, o. a. de Rijksverzekeringbank en de daarmede samenhangende instellingen.

De grootste uitbreiding ineens onderging het Pensioenfonds door de toetreding van de onderwijzers, verbonden aan het openbaar, zoowel als die verbonden aan het bizonder onderwijs ${ }^{1}$ ), welke plaats had bij de wet van 5 Juni 1905 (Staatsblad No. 153). Hierbij werd bepaald dat aan de weduwen van onderwijzers en aan hunne weezen, beneden den leeftijd van 18 jaren, een pensioen zou worden verleend, ten laste van het Pensioenfonds voor weduwen en weezen van Burgerlijke ambtenaren.

Evenals de ambtenaren betalen de onderwijzers een jaarlijksche bijdrage van $5 \mathrm{pCt}$. van hun tractement (gerekend tot een maximum van f 2.400.-). De Regeering deed terzelfder tijd afstand van het kapitaal van 4 millioen gulden,

1) $O_{p}$ ult ${ }^{\circ}$ December 1910 bedroeg het aantal onderwijzers aan het openbaar en bizonder onderwijs: 23562, waaronder 8001 vrouwen, het getal burgerlijke ambtenaren 30.809 waaronder 1639 vrouwen. 
waarvan zij de beschikking aan zich had voorbehouden.

De groote uitbreiding, welke het fonds in den loop der tijden onderging door de nieuw aangestelde ambtenaren en door de inlijving van geheele categoriën personen, was in den regel nadeelig. Dit bleek hierboven bij de onderwijzers van de Rijksnormaallessen; dit blijkt nu uit de vroegere balansen, waar op de debetzijde steeds een post voorkwam voor de nieuw aan te stellen ambtenaren, afgeleid uit den gang van zaken gedurende de laatste vijf jaren en wel op ulto December 1895,1900 en 1905 respectievelijk groot 3.5, 1.3 en 3.7 millioen gulden. De hoofdfactor in deze is de gemiddelde leeftijd bij aanstelling. Hoe hooger deze is, hoe lager de contante waarde der toekomstige bijdragen. Wordt deze overtroffen door de contante waarde der toekomstige lasten, dan moet een bepaald gedeelte van het kapitaal van het fonds speciaal aangewezen worden tot dekking van dit tekort, wanneer het fonds geen vergoeding krijgt voor die nieuwe opneming.

$\mathrm{Nu}$ toonde elk der bedoelde balansen, na aftrek van hetgeen gereserveerd werd voor de nieuw aan te stellen ambtenaren, toch nog batige saldo's, respectievelijk van $14.7,18.1$ en 4.7 millioen gulden, zoodat de opneming van nieuwe deelgerechtigden geen gevaar opleverde voor het Pensioenfonds. Evenmin werd te kort gedaan aan de aanspraken der oude deelgerechtigden, daar hunne bijdragen $(5 \mathrm{pCt}$. van den pensioengrondslag) juist voldoende is tot dekking der lasten voor hun pensioen. Hunne weduwen en weezen ontvangen het pensioen, dat overeenkomt met de bijdragen.

Bij het opmaken der vierde wetenschappelijke balans bleek, dat op 31 December 1910 de contante waarde der toekomstige bijdragen van de onderwijzers bedroeg f 20.346.203.-, die der toekomstige lasten f 29.671.710.-, alzoo f 9.325.507. - minder.

Een kapitaal, ter waarde van dit bedrag, had dus in het Pensioenfonds gestort moeten worden. De Regeering deed, als boven gezegd, afstand van de haar toekomende 4 millioen gulden, zoodat aan het fonds door de wet van 1905 een nadeel van 5.3 millioen gulden toegebracht is.

Zonder de opname der onderwijzers en na betaling aan den Staat van de meergenoemde 4 millioen gulden zou de 
vierde wetenschappelijke balans met een batig saldo van 16 millioen gulden, in stede van $10 \frac{3}{4}$, sluiten. Echter niet geheel. Want de nieuw toetredende onderwijzers brengen eenig voordeel aan. Terwijl zij jaarlijks $5 \mathrm{pCt}$. van hun tractement storten, zou een bijdrage van $4.82 \mathrm{pCt}$. voldoende zijn om evenwicht te maken met de toekomstige lasten, ten behoeve van hunne weduwen en weezen. Bij de nieuwe ambtenaren zou die bijdrage $5.08 \mathrm{pCt}$., dus iets meer dan door hen betaald wordt, moeten bedragen. Dit verschil vindt zijn oorzaak in de omstandigheid, dat de gemiddelde leeftijd bij de aanstelling tot onderwijzer (21.1 jaar voor 1905-1910) lager is dan bij die tot ambtenaar (27.7 jaar over dat tijdvak); benoemingen op later leeftijd, die bij de ambtenaren veelvuldig voorkomen, zijn bij de onderwijzers zoo goed als uitgesloten.

De bijdragen der nieuwe aanstellingen, van ambtenaren en onderwijzers tezamen, zijn meer dan voldoende om de toekomstige lasten te dragen, leveren zelfs per jaar een voordeel van ruim f 90.000.- op. Dank zij de geringere sterftekans, in verband met den jeugdigen leeftijd bij aanstelling tot onderwijzer, behoeft voor de nieuwe aanstellingen geen reservepost op de balanis meer voor te komen, wanneer het fonds zich verder zal ontwikkelen, zooals de laatste jaren is geschied.

De mogelijkheid, dat de gemeente-ambtenaren te eeniger tijd zullen worden opgenomen in het Pensioenfonds, is niet uitgesloten. Welke zouden de gevolgen daarvan zijn?

In het verslag der Heeren Mulder en Zoot is becijferd, dat op 31 December 1907 de contante waarde der lasten om aan de toenmalige gemeente-ambtenaren, behalve die van Amsterdam en Rotterdam, een weduwe- en weezenpensioen te verzekeren op denzelfden voet als de burgerlijke ambtenaren, 18.5 millioen gulden bedroeg, de contante waarde hunner bijdragen 11.6 millioen gulden, dus een tekort van 6.9 millioen gulden zou opleveren. Amsterdam en Rotterdam zijn hierbij niet opgenomen omdat deze gemeenten een pensioenfonds voor weduwen en weezen harer ambtenaren hebben. Ook bij een groot aantal andere gemeenten zijn pensioenfondsen of is er op een andere wijze voor de weduwen en weezen der ambtenaren gezorgd. 
In een duizendtal gemeenten met ongeveer $10000 \mathrm{amb}$ tenaren is nog niets voor de weduwen en weezen gedaan. Het aantal ambtenaren bij alle gemeenten in Nederland, behalve Amsterdam en Rotterdam, bedroeg op 31 December 1907 nagenoeg 24000; voor meer dan de helft bestond dus reeds een weduwen- en weezenzorg. Het voormelde getal van $6.9 \mathrm{kan}$. dus veilig op 4 gesteld worden.

De opneming van de bestaande gemeente-ambtenaren in het weduwen- en weezenfonds zou dus tegen 4 millioen gulden ingekocht kunnen worden.

Vermoedelijk kan die som nog iets lager gesteld worden, daar bij het opmaken der berekeningen de H.H. Mulder en Zoot geen gebruik konden maken van de sterftetafels, die gebezigd zijn bij de vierde wetenschappelijke balans en die een veel gunstiger resultaat opleveren dan de oudere sterftetafels.

Dit is ook het geval met de nieuwe aanstellingen bij de gemeenten. Door genoemde heeren werd berekend, dat door de gemeente-ambtenaren $6 \mathrm{pCt}$. gestort zou moeten worden in een eventueel op te richten pensioenfonds; bij herberekening met de nieuwere gegevens van de vierde wetenschappelijke balans zal vermoedelijk blijken dat een bijdrage van 5 pCt., evenals bij de burgerlijke ambtenaren, voldoende zal zijn. ${ }^{1}$ ) Dan zou dus de oplossing van het vraagstuk der pensionneering van weduwen en weezen der gemeente-ambtenaren kunnen zijn, dat voor de bestaande ambtenaren, van de plm. 1000 gemeenten, die geen pensioenregeling hebben, een kapitaal van plm. 4 millioen gulden gestort zou worden in het pensioenfonds voor weduwen en weezen der Burgerlijke Ambtenaren, en dat alle nieuw aangestelde gemeente-ambtenaren tegen een bijdrage van $5 \mathrm{pCt}$. tot dat fonds toetraden.

Daarbij zou evenwel noodig zijn een maximum voor den leeftijd van toetreden te bepalen of wel de bijdrage progressief te maken voor leeftijden boven een zekere grens.

De bestaande gemeentepensioenfondsen voor weduwen en weezen zouden voor verdere deelneming gesloten kunnen worden.
Juni 1912.
H. T. Hoven.

1) Hierbij is niet gerekend op een nieuwe verhooging der weduwenpensioenen. 